\title{
A Comparative Study of Psychiatric Disorders among Mothers of Children with Chronic Diseases and Mothers of Healthy Children
}

\author{
Zohreh Eskandari Shahraki ${ }^{1}$, Mohammad Efffatpanah ${ }^{2 *}$, Serajaddin Gray $^{3}$, Mitra Radfar ${ }^{4}$, Mehdi Rezaei $^{5}$, \\ Hamidreza Hekmat ${ }^{2}$, Shokofeh Radfar ${ }^{6}$ \\ ${ }^{1}$ Department of Clinical Psychology, Qazvin Branch, Islamic Azad University, Qazvin, Iran. \\ ${ }^{2}$ School of medicine, Ziaeian hospital, international campus, Tehran University of Medical Sciences, Tehran, Iran. \\ ${ }^{3}$ Department of Health Management and Economics, School of Public Health, Tehran University of Medical Sciences, Tehran, Iran. \\ ${ }^{4}$ Imam Hossein medical center, Shahid Beheshti University of Medical Science, Tehran, Iran. \\ ${ }^{5}$ Orthopedic surgery department, School of medicine, Tehran University of Medical Sciences. \\ ${ }^{6}$ Bagiyatallah hospital, Baqiyatallah University of Medical Sciences, Tehran, Iran.
}

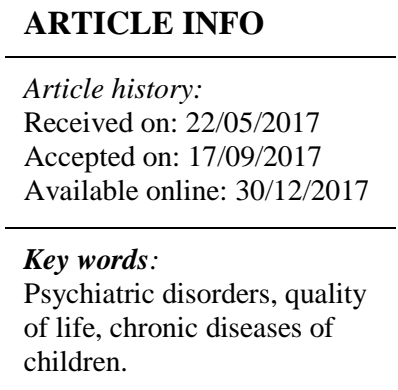

\begin{abstract}
The current study was conducted to compare the psychiatric disorders in mothers of children with a chronic disease with mothers of healthy children. The study was observational-analytical case-control study. The study population included mothers of chronically ill children who were hospitalized in internal wards of the Tehran Children Medical Center and mothers of normal children who referred to the Dental Clinic of this center. For sampling, convenience sampling method was used and127 mothers were selected (65 mothers of healthy children and 62 mothers of ill children). The instrument used was SCL-90-R and demographic questionnaires. The collected data were analyzed using descriptive statistics and multivariate analysis of variance. The results showed that mothers of children with chronic disease had a significant difference in all components of psychiatric disorders $(\mathrm{P}<0.05)$ with mothers of healthy children. $55.2 \%$ percent of mothers of ill children had morbid psychiatric versus $34.5 \%$ of mothers in the control group.
\end{abstract}

\section{INTRODUCTION}

Mental disorder is a syndrome that its main characteristics include disruption of cognition, loss of emotional control or behavior, and disorder of psychotic or biological processes underlying mental functioning (Diagnostic and Statistical Manual of Mental Disorders, 2013). According to studies conducted by the World Health Organization (WHO), $20 \%$ of the population in developing countries suffer from depression. Also, according to the WHO reports, mental disorder is $26 \%$ among Iranian women (Gelder and Geddes, 2005). Chronic diseases (non-communicable diseases such as diabetes, heart disease, chronic obstructive pulmonary disease, cancer,

* Corresponding Author

Email: M.effatpanah@gmail.com depression, and communicable diseases such as AIDS, etc.) have different characteristics, including: long waiting period, the long incubation, continuous clinical processes, multifactorial etiology, without a definite cure, gradual changes over time, the inconsistent and heterogeneous evolution of disease in the populations at risk of chronic disease (Bentzen, 2003). National health interview survey (NHIS) data indicate that $30 \%$ of children suffer from chronic health problems in the United States from 2000 to 2003. Once in a family, a person is diagnosed with a chronic illness, it is naturally that other family members feel anger, denial, blame themselves and others, fear, shock, confusion and distress. Because parents of children consider themselves and the environment responsible for a child's illness and suffer through anxiety, guilt, helplessness and powerlessness and therefore is affected their performance and ultimately of the whole family (Ellenwood and Jenkins, 2007). Despite the variety of social services, primary care of patients with chronic diseases were done by family members (Smith, 2007). 
More than $40 \%$ of family members of patients with chronic diseases (particularly cancer), show somatoform disorders and post-traumatic stress disorder symptoms. Caregivers of children with chronic disease often have poor quality sleep, high stress and pressure, which lead to an overall reduction in life quality (Klassen et al., 2008). Since physical health of the child affects mother's behavior and performance, Rhodes et al (1999) reported that mothers of children with epilepsy are more likely to show aggression and anger towards their sick child. Streisand et al (2000) also found that mothers with children who need bone marrow transplants, need a lot of counseling and psychotherapy to reduce their anxiety. Shu et al (2000) studied the effect of autistic children on the mental health of mothers and found that mothers of children with Autism experience more stress and were more prone to depression and anxiety compared to mothers of children with other diseases.

Miodrag and Hodapp (2011) found that parents of children with intellectual or developmental disability, had chronic stress disease. Caregivers of children with chronic illness may often report poor quality sleep, stress and high pressure that leads to a reduction of life quality (Klassen et al., 2008).In study of Soltanifar et al (2010), the results showed that $80 \%$ of mothers of children with anxiety disorders were suffered an anxiety or mood disorder. This indicate that depending on the type of disease in children, there might be various types of mood disorders in parents; the more severe the disease, the higher anxiety and depression in parents might be visible. There are numerous studies that reported an association between psychiatric disorders of mothers with chronic diseases of their children (Minkovitz et al., 2005; Bartlet et al., 2004; Streisand et al, 2008).

Since the presence of a physically ill child has negative effects on the parents' life and family members and can create long-term consequences and many disrupting covert and overt changes in various aspects of life of family members, it is important to pay attention to the health of mothers and identify its obstacles. In the majority of studies people with chronic disease are studied, and few of them studied the prevalence of different aspects of psychiatric disorders (often only anxiety and depression) in mothers of children with chronic disease, the present study was designed to compare psychiatric disorders in mothers of children with chronic diseases with mothers of normal children.

\section{MATERIALS AND METHODS}

The statistical population of the current study included mothers of children that referred to the Tehran Children Medical Center. The sample was selected from mothers of children with chronic diseases hospitalized in internal wards as the experimental group, and mothers of healthy children who referred for child's dental treatment in this center. Due to $25 \%$ significant diagnostic differences between the two groups, $80 \%$ statistical power and 0.05 error type 1,the sample size of the current study was determined 55 persons in each group using Cochrane formula; however,to prevent the unintended effect of reducing the sample size in each group, 70 questionnaires were distributed among mothers.

In order to check the status of the samples' psychiatric symptoms, SCL-90-R questionnaire was used (Derogatis et al., 1985).The questionnaire contains 90 questions which are scored based on five options Likert scale (none, slightly, to some extent, high and very high). The ratings were based on scores zero (none), 1 (slightly), 2 (to some extent), 3 (high) and 4 (very high).Dimensions of questionnaire included somatic complaints (12 items), obsessive-compulsive (10 items), interpersonal sensitivity ( 9 items), depression (13 items), anxiety (10 items), aggression (6 items), phobia (7 items), paranoia thoughts (6 items), psychosis (10 items) and clinical situation ( 7 items).Various studies have reported that reliability of this questionnaire was estimated more than 0.77 base on Cronbach's alpha (Deragotis, Rickels, 1976; Deragotis, 2000; Rezapour, 1997; Ismail, 1997; Fathi, 2009). A researcher-made demographic questionnaire also was included: child's description (including age, gender, birth order, date of diagnosis of disease, type of chronic disease and lack of mental disability) and mother's status (age, place of residence, educational level, socioeconomic status, marital status, employment status and lack of mental disability).Frequency, mean, standard deviation and percent were used as descriptive statistics. Kolmogorov-Smirnov and M Box's tests were used for normality distribution of data and homogeneity of variance, respectively. One way analysis of variance was used to compare the two groups.

\section{Ethical considerations}

Details of the experiment were described to the patient and then informed consent was obtained from the patient. The experiment was approved by the Ethics Committee of Tehran University of Medical Sciences.

\section{RESULTS AND DISCUSSION}

The mothers of healthy children $(n=65), 95.5 \%$ were married and $46 \%$ were divorced and the mothers of sick children $(\mathrm{n}=62)$ were $100 \%$ married. In the experimental group, mothers at the age of $31-35$ years old $(30.8 \%)$ was the highest frequency and mothers at 41-45 years old was the lowest frequency (3.2\%). Mothers of healthy children in the age group 31-35 years oldwas $36.9 \%$ and ages 41-45 and 21-25 were 4.5\%. Overall, frequency of age range of $31-35$ years old were $33.8 \%$ in 127 person. In terms of education, $44.6 \%$ of healthy children's mothers and $45.2 \%$ of sick children's mothers had a high school education and diploma. In sick children's mothers group, the level of education of mothers was as follows: elementary $9.7 \%$, pre-high school $27 \%$, diploma (6.5\%), bachelor's degree $11.3 \%$; and at the control group were: elementary 1\%, pre-high school7.7\%, associate diploma $16.9 \%$ and bachelor's degree and higher $3.1 \%$.Also, according to the number of offspring of mothers with healthy children, the results were:55.4\% with one child, $35.34 \%$ two children, and $6 \%$ three children; and in mothers of sick 
children were: $41.9 \%$ one child, $51.6 \%$ two children, $4.8 \%$ three children, and $1.6 \%$ four children. The majority of mothers with sick children had one child, and the majority of mothers of healthy children had two. In terms of gender of children, mothers of healthy children, mostly had daughter $(55.4 \%)$ and the majority of the other group had son (59.7\%).

In terms of employment status of mothers, $80 \%$ of the control group and $95.5 \%$ of mothers of sick children were housewives. In terms of income, the majority of mothers of healthy children had middle income $(73.8 \%)$ and the low income was the lowest frequency $(1.5 \%)$. In the group of mothers of sick children, middle-income was $45.2 \%$ and very high income was $3.2 \%$ and followed by very low income was $6.5 \%$. In terms of children's age, healthy children with lower than 5 years old $(35.4 \%)$ and 5-10 years old $(64.4 \%)$ had the most frequency. In sick children, the most frequent age was under the age of 5 years $(54.4 \%)$, followed by $10-15$ years old $(22.5 \%)$ and $5-10$ years old $(19.3 \%)$

In terms of the place of living, the majority of mothers of healthy children $(80 \%)$ were living in Tehran. The majority of patients' mothers $(35.5 \%)$ were living around Tehran. Other cities and villages were $32.3 \%$ and $6.5 \%$, respectively. The frequency of children, according to the type of disease were shown in Table 1. Overall of 62 questionnaires were answered by the mothers of sick children who mostly belonged to the Hematic diseases. In order to do statistical parametric analysis, Kolmogorov-Smirnov normality test was performed and showed that all data had normal distribution $(\mathrm{P}>0.05)$ (Table 2).

Table 1: Distribution of children by type of disease.

\begin{tabular}{cc}
\hline Disease & $\boldsymbol{\%}$ \\
\hline Hematic & 25.8 \\
Respiratory & 4.83 \\
Digestive & 9.67 \\
Heart & 4.83 \\
kidney and lymph & 12.9 \\
Neurological & 17.74 \\
Rheumatology & 11 \\
Urology & 11.29 \\
\hline
\end{tabular}

Table 2: investigating the normality of the data by Kolmogorov-Smirnov test.

\begin{tabular}{cccc}
\hline Components & $\mathbf{Z}$ & $\mathbf{P}$ & Distribution \\
\hline Psychiatric disorders & 1.08 & 0.192 & Parametric \\
\hline
\end{tabular}

Psychiatric disorders in mothers with sick children and mothers with healthy children were shown in table 3 . The majority of mothers of healthy children had no psychiatric disorders and the majority of mothers with sick children showed psychiatric disorders. To evaluate the significant difference between the prevalence of psychiatric disorders in mothers of children with chronic diseases with mothers of healthy children, the multivariate analysis of variance was used. The results of the multivariate variance analysis (table 4) showed that there was a significant difference between the mean of psychiatric disorders and its components in both groups. According to the average, psychiatric disorders were higher in mothers with sick children.
Based on the results, it was found that paranoia thoughts (1.09) and aggression (0.70) had the highest and lowest frequencies in mothers of healthy children, respectively. Depression (1.85) and phobia (0.94) had the highest and lowest average in mothers with sick children, respectively.

Table 3: Distribution of frequency of prevalence of psychiatric disorders in mothers.

\begin{tabular}{|c|c|c|c|c|}
\hline $\begin{array}{l}\hat{\Xi} \\
\stackrel{0}{0}\end{array}$ & Components & 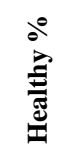 & 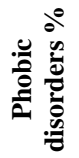 & 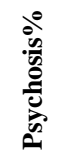 \\
\hline \multirow{10}{*}{ 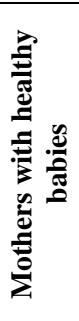 } & Physical complaint & 64.8 & 33.7 & 1.5 \\
\hline & Obsessive-compulsive & 59.9 & 40.1 & 0 \\
\hline & Interpersonal sensitivity & 72.5 & 27.7 & 0 \\
\hline & Depression & 64.7 & 30.5 & 4.5 \\
\hline & Anxiety & 58.8 & 39.8 & 1.5 \\
\hline & Aggression & 77 & 33 & 0 \\
\hline & Phobia & 87.7 & 12.3 & 0 \\
\hline & Paranoia & 43.7 & 15.5 & 4.8 \\
\hline & Psychosis & 77 & 21.3 & 1.5 \\
\hline & Psychiatric disorders & 63 & 34.5 & 0 \\
\hline \multirow{10}{*}{ 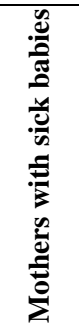 } & Physical complaint & 30.5 & 59.9 & 9.6 \\
\hline & Obsessive-compulsive & 30.5 & 62.8 & 6.4 \\
\hline & Interpersonal sensitivity & 45.1 & 49.8 & 4.8 \\
\hline & Depression & 22.4 & 67.3 & 9.6 \\
\hline & Anxiety & 62.8 & 25.6 & 11.2 \\
\hline & aggression & 63 & 32.1 & 4.8 \\
\hline & Phobia & 59.8 & 38.6 & 1.6 \\
\hline & Paranoia & 54 & 41.5 & 4.5 \\
\hline & Psychosis & 59.6 & 35.4 & 4.8 \\
\hline & Psychiatric disorders & 40 & 55.2 & 4.8 \\
\hline
\end{tabular}

Table 4: test results in mothers of children with chronic disease compared to mothers of healthy children.

\begin{tabular}{lccccc}
\hline Variables & \multicolumn{2}{l}{ Mean of mothers with } & $\begin{array}{l}\text { Sum of } \\
\text { squares }\end{array}$ & F & Sig. \\
\hline babies & $\begin{array}{l}\text { Sick } \\
\text { babies }\end{array}$ & 1.61 & 17.38 & 26.54 & 0.001 \\
\hline $\begin{array}{l}\text { Physical } \\
\text { complaint }\end{array}$ & 0.88 & 1.62 & 16.36 & 25.37 & 0.001 \\
$\begin{array}{l}\text { Obsessive- } \\
\text { compulsive }\end{array}$ & 0.91 & 1.31 & 8.99 & 14.61 & 0.001 \\
$\begin{array}{l}\text { Interpersonal } \\
\text { sensitivity }\end{array}$ & 0.78 & 1.85 & 26.79 & 30.99 & 0.001 \\
$\begin{array}{l}\text { Depression } \\
\text { Anxiety }\end{array}$ & 0.94 & 1.72 & 22.79 & 30.31 & 0.001 \\
aggression & 0.88 & 1.04 & 3.73 & 5.86 & 0.017 \\
$\begin{array}{l}\text { Phobia } \\
\text { Paranoia }\end{array}$ & 0.7 & 0.942 & 8.23 & 21.75 & 0.001 \\
Psychosis & 1.09 & 1.44 & 3.85 & 4.76 & 0.031 \\
$\begin{array}{l}\text { Psychiatric } \\
\text { disorders }\end{array}$ & 0.7 & 1.04 & 3.75 & 5.38 & 0.022 \\
\hline
\end{tabular}

In general, the average scores of all disorders except phobia (0.94) were morbid and above one in the mothers of sick children. According to the definition of morbidity in this research (i.e. the mean scores above 1), 55.2\% of mothers of sick children were in the morbidity status in terms of mental health disorders, and according to the definition of neurosis (i.e. mean scores above 3 in patients), $8.4 \%$ of mothers suffer from neurosis; and $40 \%$ of them were in mental health. This finding is match with Ghazavi's study (1999). The results of Mohammadi (2001) are somewhat similar, that may be due to ethnic differences of the various 
regions and the possibility of more limited facilities of these regions in the maintenance of children with disabilities.

In mothers of healthy children, the mean score of all disorders except Paranoid thoughts (1.09) was under one. In terms of psychiatric disorders in mothers of healthy children, $63 \%$ were healthy, $34.5 \%$ showed morbidity and none suffered from neurosis.

The results indicate that components of psychiatric disorders, included somatization $(\mathrm{p}=0.001, \mathrm{~F}=26.5)$, obsessivecompulsive $(\mathrm{F}=25.37, \mathrm{p}=0.001)$, interpersonal sensitivity ( $\mathrm{F}$ $=14.61, \mathrm{p}=0.001)$, depression $(\mathrm{F}=30.99, \mathrm{p}=0.001)$ anxiety $(\mathrm{F}$ $=30.31, \mathrm{p}=0.001)$, aggression $(\mathrm{P}=0.017, \mathrm{~F}=5.86)$, phobia $(\mathrm{F}$ $=21.75, \mathrm{P}=0.001)$, paranoid thoughts $(\mathrm{P}=0.31, \mathrm{~F}=4.76)$ and psychosis $(\mathrm{F}=5.38, \mathrm{P}=0.022)$ and mothers of children with chronic diseases compared to mothers of healthy children show significant differences. According to the highest average scores in mothers of sick children, the prevalence of these disorders was higher in them. Thus, the research hypothesis is confirmed.

The results of the current study on significant differences in the mean scores of mothers of healthy children in comparing to mothers of children with chronic disease in terms of depression and anxiety are match with the following studies: Khajehpour (1998) showed that neurotic reactions (depression, anxiety and hostility) in mothers of disabled children is more than normal; Kousha et al (2015) on mothers of children with autism spectrum disorder; Shahmorady (2015) in parents of children with thalassemia Major; Shafa'at (2011) on mothers of children with hyperactivity and ADHD; Saiah (2010) on parents of children with cancer; Ashkani et al (2004) in parents of children with chronic diseases; Bailey et al (2007) in parents with mental retardation, Christine et al. (2014) on mothers of infants with pulmonary dysplasia; Gallagher et al. (2010) on caregivers of children with developmental disabilities; Bakiet al (2004) in parents of adolescents with epilepsy, Mash and Jonston (1983) on parents of children with hyperactivity compared to mothers of normal children, Soltanifar et al (2010) on parents of children with anxiety disorder. However, these values are somewhat different due to the severity of illness and the problems of mothers of children with chronic illness. In the study of Kheirabadi et al (2007) the prevalence of depression in mothers of children with asthma and diabetes have been reported 27 and 30\%, respectively; which is different with the present study.

In the study by Habrani (2003) the prevalence of depression in parents of children with attention deficit hyperactivity is similar to the present study. The result of Narimani et al (2006) also is consistent with the present study that depression, anxiety, psychosis, aggression and phobia of mothers of blind and deaf children were significantly higher than mothers of normal children.

Lamb (1991) and Hodas et al. (1979) also indicated that aggression of mothers of disabled children was higher than mothers of normal children. Shan Leung\& Li-Tsang (2003) showed that there is a positive relationship between parents' quality of life and level of disability of children. Parents of more severe disabilities children have more stress than mothers of normal children.

\section{CONCLUSION}

Children with chronic diseases and the medical methods used for their treatment, impose unpredictable psychological pressures on the lives of their families. The current study showed that physical complaint, Obsessive-compulsive, Interpersonal sensitivity, Depression, Anxiety, aggression, Phobia, Paranoia, Psychosis and Psychiatric disorders were higher in mothers of sick children. Therefore, the country's treatment and supportive systems should pay particular attention to these families so that other family members of these children are less likely to suffer mental illness.

\section{Financial support and sponsorship: Nil.}

Conflict of Interests: There are no conflicts of interest.

\section{REFERENCES}

Ashkani H, Dehbozorgi Gh R, Tahamtan A. Depression among Parents of Children with Chronic and Disabling Disease. Iran J Med Sci, 2004, 29(2): 90-93.

Bailey JRDB, Golden RN, Roberts J, Ford A. Maternal depression and Developmental disability: Research critique, $J$ of the Mental Retard and Developmental Disabi Resea Revi, 2007, 13 (4), 321329.

Baki O, Erdogan A, Kantarci O, Akisik G, Kayaalp L, Yalcinkay C. Anxiety and depression in children with epilepsy and thire mothers. Epilepsy Behav, 2004, 5(6): 640-958

Bartlett S J, Krishnan J A, Riekert K A, Butz A M, Malveaux F J, Rand C S. Maternal depressive symptoms and adherence to therapy in inner-city children with asthma. Pediatrics, 2004, 113(2): 229-370.

Bentzen N. 2003. Dictionary of general/family practice. Trondheim, Norway: WONCA. International Classification Committee.

Christine A Feely, Anne T, Becky JC, Kristin TA, Karen H, David L, Xiaogang S. Sleep quality, stress, caregiver burden, and quality of life in maternal caregiver of young children with bronchi- pulmonary dysplasia. J Pediatric Nursing, 2014, 29(1):29-38 .

Colver A. Measuring quality of life in studies of disabled children, Journal of padeiatrics and child-health, 2008, 18(9): 423-426.

Derogatis L R, Lipman R S, Covey L. Scl 90: an out Patient psychiatric rating scale. Psy-chopharmacological Bulletin, 1973, 9: 13-27.

Derogatis L R, Rickels K, Rake A. The scl-90 and the MMPI a step in the validation of a new self-report scale. Brit. J. Psychiat. 1984, 128: 280-289.

Derogatis LR. 2000. Symptom Checklist-90-Revised In handbook of psychiatric measures. American Psychiatric Association, 8184 .

Ellenwood AE, Jenkins JE. Unbalancing the effects of chronic illness Non -traditional family therapy assessment and intervention approach. The American Journal of Family Therapy, 2007, 35: 265- 271.

EsmaeiliGh. 1997. Standardization of SCL-90-R and comparing the mental health of college students in Tehran to provide appropriate counseling services. MA thesis, general psychopathology. Allameh Tabatabaei University of Tehran.

Fathi Ashtiani A, Dastani M. 1998. Psychological tests: personality evaluation and mental health. $1^{\text {st }}$ ed. Tehran, Bethat, 400 .

Gallagher S, Phillips AC, Carroll D. Parental stress is associated with poor sleep quality in parents caring for children with developmental disabilities. Journal of Pediatric Psychology, 2010, 35: 728-737. 
Gelder MR, Geddes J. 2005. Oxford Text Book of Psychiatry. 1 ed. Italy: Oxford university press.

Ghazavi Z, Nasiri M. Comparing the problems of parents of mentally retarded children in Isfahan in 1994. Scientific Journal of Nursing \& Midwifery Faculty of Isfahan, 1999, 22-16.

Habrani P. 2001. Determining the pattern of psychiatric disorders in families of children with attention deficit hyperactivity. Doctoral thesis on specialty of child psychiatry, Tehran University of Medical Sciences and Health Services.

Hodas G. and Liebman R. 1978. Psychosomatic disorders in children: structural family therapy. Psychosomatics, 19, 11-21.

Khajehpour M. 1998. Analysis and comparison of neurotic reactions in mothers of normal children compared to mothers of children with mental retardation in Ahwaz. MA thesis in General Psychology. Islamic Azad University of Ahwaz.

Kheirabadi GR, Malekian A, Fakharzadeh M. 2007. Prevalence of depression in mothers of children with asthma and mothers of children with type I diabetes. Journal of Behavioral Sciences, V 5, No. 1. pp. 21-26

Klaassen AF, Klaassen R.Impact of caring for a child with cancer on parents, health- related reality of life. Journal of Clinical Oncology, 2008, 26(36): 5884- 5889.

Kosha M, Alizadeh Attar H, and Shoar Z. Anxiety, depression, and quality of life in iranian mothers of children with autism spectrum disorder. Jornal of Child Health Care, 2015, 1-10.

Lamb M, Meyer D. 1991. Families of children with special needs. In M, Seligrnan (ED), The Family with Handicpped child Boston, Allyn and Bacon.

Mash EJ, Johnston C. Parental perceptions of child behaviour problems, parenting self- esteem, and mother's reported stress in younger and older hyperactive and normal children. Journal of Consulting and Clinical Psychology, 1983, 51(1), 86-99.

Minkovitz CS, Strobino D, Scharfstein D, Hou W, Miller T, Mistry KB, et al.. Maternal depressive symptoms and children's receipt of health care in the first 3 years of life. Pediatrics, 2005, 115(2):306314.

Miodrag N, Hodapp R. 2011.Chapter Four - Chronic Stress and its Implications on Health among Families of Children with Intellectual and Developmental Disabilities (I/DD). International Review of Research on Developmental Disabilties, 41, 127-161

Mohammadi MR, Gharaie M, Alavi Shoushtari A. 2008. Final Report of prevalence of psychiatric disorders in children and adolescents in Tehran. Research Center of Psychiatry and Psychology. Tehran University of Medical Sciences.

National Health Interview Survey. 2000-2003. National center for Health Statistical, Centers for Disease Control and Prevention. http://www.Ketabpezeshki.com/ 66485457- 66963820

Rezapour M. 1999. Standardization of R -90- SCL test on students of Shahid Chamran University of Ahwaz and Ahwaz Islamic Azad University. MA thesis, University of Isfahan.
Sayah Ghorbani G. 2010. Comparison of Psychiatric (depression, post-traumatic stress disorder)-cognitive (autobiographical, prospective memory) functioning and family functioning of parents of children with cancer and parents of normal children. Master's thesis, University of Knowledge and Culture.

Shafa'at A. Prevalence of depression in mothers of children with attention deficit hyperactivity disorder in Adolescent Psychiatric Clinic in Sari. Mazandaran University of Medical Sciences, 2011, 21: 6672 .

Shahmorady Vali. 2015. Risk Factors influencing the behavior of parents and children with thalassemia major in Arak. Master's Thesis, Arak University of Medical Sciences.

Shan Leung CY, Li-Tsang CWP. Quality of life of parents who have children with disabilities. Hong kong Journal of Occupational Therapy, 2003, 13(1): 19-24.

Shu BC, Lung FW, Chang YY. Parental psychiatric disorder: effects on children. Kaohsiung Journal of Medical Science, 2000, 16: 308314.

Smith M, Greenberg J, Mallick SM. Siblings of adults with schizophrenia: Expectations about future care giving roles. American Journal of Ortho psychiatry, 2007, 77: 29-37.

Soltanifar A, Rezaie Erdani A, Jafarzadeh Fadaki SM. (). A case-control study on anxiety and depression in parents of children with anxiety disorders. Journal of Psychiatry scientific principles, 2009, 11(1): 51-60.

Specilized Forum of Psychiatric disorders. 2016. Diagnostic and Statistical Manual of Psychiatric Disorders (5- DSM).

Streilsand R, Mackey ER, Elliot BM, Mednick L, Slaughter IM, Turek J, et al.. Parental anxiety and depression associated with caring for a child newly diagnosed with type1 diabetes: Opportunities for education and counseling. Patient education and counseling, 2008, 73(2):333-338.

Streisand R, Rodrigue J R, Houck C, Graham PJ, Berlant N. Brief report: parents of children undergoing bone marrow transplanta-tion: documenting stress and piloting a psycho-logical intervention program. Journal of Pediatric Psychology, 2000, 25: 331-337.

\section{How to cite this article:}

Shahraki ZE, Efffatpanah M, Gray S, Radfar M, Radfar S. A Comparative Study of Psychiatric Disorders among Mothers of Children with Chronic Diseases and Mothers of Healthy Children. J App Pharm Sci, 2017; 7 (12): 116-120. 